\title{
Green Business Models Transformation: Evidence from the UK
}

\section{Construction Sector}

\begin{abstract}
Purpose - Sustainability has the potential to bring enormous benefits to our built environment. To release this potential, a change in business models is required. Green business models (GBMs) transformation is investigated by adopting five essential elements of green value creation and capture: Green Value proposition (GVP), Target Group (TG) Key Activities (KA), Key Resources (KR), and Financial Logic (FL).

Design/methodology/approach - In this qualitative study, 19 semi-structured interviews are conducted. Interviewees were selected purposively. The emergent data is analysed with the aid of themes.
\end{abstract}

Findings - It is observed that significant effort is being made towards enabling the transformation of certain elements pertinent to green value creation: KA and KR. This is particularly so when compared to other elements like GVP, TG, and FL.

Implications -Findings from this study should encourage construction managers to align their extant BMs to green activities hence enabling new approaches to green value creation and capture. Furthermore, the study will aid in improving the environmental and economic positions of the value chain within the construction sector.

Originality/value - This research is one of the few empirical academic works investigating GBMs in the construction sector.

Keywords Construction sector, Exploratory study, Green business model, UK, Transformation, Value chain.

Paper type Research paper

\section{Introduction}

The construction sector plays a vital role for most human activities. The quality of the built environment has an impact on the quality of people's lives (Raynsford, 1999). In the UK, the construction sector remains central to the national economy. According to Rhodes (2014), the sector accounts for $6 \%$ of the economic output and provides employment for $6.5 \%$ of the population. Consequently, it makes a significant contribution to the attainment of sustainable development goals (Selberherr, 2015). Sustainability has the power to fundamentally transform the construction sector (Aho, 2013).Green Business Models (GBMs) have the 
potential to deliver the desired sectorial transformation by changing the way the firm and its value chain create, deliver, and capture value (Bocken et al., 2014).. However, GBMs lack a widely accepted definition in the literature (Henriskin et al., 2012). Previous studies have applied the business model (BM) concept to understand green/sustainable construction (Aho, 2013; Mokhlesian \& Holmen, 2012). This study differs from other studies by focusing empirically on GBMs transformation within the UK construction sector by utilising a set of elements: Green Value proposition (GVP), Target Group (TG) Key Activities (KA), Key Resources (KR), and Financial Logic (FL). The elements were adopted from the management and business literature because they were developed specifically for GBMs arising in different sectors (Sommer, 2012). The guiding question of this study is: how do construction firms transform their BMs towards attaining environmental sustainability? The purpose of this work is to help construction managers review their current activities and adjust their BMs to align them to a greener alternative (GBM).

The remainder of this article is structured as follows: a review of the BM/GBM literature is presented in Section 2. The research methodology is discussed in Section 3. Section 4 draws on empirical data from the UK construction sector to explain GBMs transformation with its implications in Section 5. Conclusions are rendered in Section 6.

\section{Literature Review}

\subsection{The Business Model (BM) Concept}

The e-business movement recognized the $\mathrm{BM}$ as a bona fide management concept (Osterwalder, 2004). "A business model describes the rationale of how an organisation creates, delivers, and captures value." (Osterwalder \& Pigneur 2010, p.14).

Despite evolving from the e-business discipline, the concept's usefulness across several disciplines has continued to resonate in contemporary studies (Lambert \& Davidson, 2013). Teece (2010) suggests that the BM concept is relevant for researchers trying to examine the logic behind economic value creation. Recently, the BM has gained popularity in the construction research and started with ICT and e-commerce in the construction sector (Pan \& Goodier, 2011). Recent studies in the construction research introduced the BM concept to sustainability/ green transition. For example, Zhao \& Pan (2015) suggested the BM approach as a path to increase zero carbon buildings uptake. Walravens (2015) proposed BMs for smart city based on value network and public value. In addition, Selberherr (2015) 
conceptualised BMs for sustainable construction by viewing the sector as cooperation network. However, this study deals with GBMs inclusively. It adopts five essential elements of the GBM and provides empirical evidence from the construction sector on the transformation of each element to embed environmental sustainability within the whole BMs.

\subsection{Green Business Models (GBMs)}

Research on GBMs can best be described as being at an embryonic stage (Sommer, 2012). With the exception of Henriskin et al., (2012) and Sommer (2012), previous studies have not presented a structured approach for describing the GBM concept. The literature generally frames GBMs within the context of changing BM elements and the discovery of new approaches to green value creation and capture (Jing \& Jiang, 2013; Sommer, 2012). Such changes are expected to bring about environmental and economic benefits.

Relying on seven case studies, Sommer (2012) discusses GBMs from theoretical and empirical perspectives. According to him, a GBM can be defined as "a business model that represents a significant improvement (discontinuous leap) in overall environmental performance relating to its entire value chain system vis-à-vis that of conventional business model (i.e., the reference case). This improvement is directly attributable to the business model through the alternative design and configuration of business models elements" ( $\mathrm{p}$. 106). Henriskin et al. (2012) defines GBMs as innovation during which a firm changes element (s) of its BM to capture economic value and reduce ecological footprint. These definitions indicate that GBMs have lower environmental impacts and suggest that a change in elements of conventional BM is required for GBMs. The introduction of the GBM concept into the construction sector is premised upon these observations.

Consequently, the transformation of a BM into a GBM entails the presence of certain elements. However, researchers have different perceptions of these elements. For instance, Aho (2013) suggests five elements: value proposition; customers; resources; capabilities; and revenue stream in dealing with added value of sustainable buildings. Mokhlesian and Holmen (2012) adopt nine elements to understand green construction processes: value proposition, target customer, customer interfaces, customer handling, value configuration, capability, partner network, cost structure, and revenue model. Furthermore, Sommer (2012) suggests five basic elements of GBMs: GVP, TG, KA, KR, and FL. He also identifies two value perspectives of GBMs: green value creation and capture. Green value is created by 
assembling a bundle of KR and KA which, when combined, will create value for clients or users. This combination will be done partly within and partly outside the firm (Mokhlesian \& Holmén, 2012). The outcome will be a GVP that will be offered to TG hence generating revenue streams. This determines the value capture for the firm (Aho, 2013). This study relies on Sommer's conceptualisation given his approach to inclusive GBMs through a theoretical and empirical perspective of different sectors (Sommer, 2012). Table 1 presents brief overview of the GBM elements.

[Table 1]

The elements in Table 1 were used as an analytical framework to collect data to understand the transformation of each element as a result of green activities.

\section{Research methodology}

This study explores the transformation of the UK construction sector's extant BM into a GBM status. As such, the qualitative approach appears most useful because it produces a wealth of detailed data from a small sample. ( Denzin \& Lincoln, 2008; Hyde, 2000). Furthermore, data collection is not restricted to predetermined themes alone but allows for the introduction of emergent themes (Bryman, 2012). Additionally, qualitative data has often been advocated as the best approach for discovering new frontiers based on its potential for knowledge creation (Amaratunga et al., 2002). These features are well aligned with this study's aim hence making the selection of this approach a natural choice. Data were collected through semi-structured interviews. Semi-structured interviews are important tools for gaining a realistic insight into an individual's world view (Renukappa et al., 2012). This was the case in this study as it sought to understand the transformation process from the perspectives of UK construction stakeholders. Interviewees were purposively selected (Creswell, 2007).

A total of 40 individuals were approached through emails and telephone calls. The selection criteria were as follows:

- Senior/managers in the construction industry

- Relevant experience in sustainability strategies and practices 
- A decision maker regarding sustainability issues, for example, being able to initiate and implement future plans

- Ideally, a sustainability manager, expert or officer.

An introductory letter and an interview guide were emailed to these individuals for clarity. However, 19 individuals indicated interest and were interviewed. This sample comprised of professionals representing six stakeholder groups in the UK construction sector: Academics (A), Architects (AR), Consultants (CS), and Contractors (C). Others (O) include property development and procurement, and Client (CL). Of these 19 interviews, three interviews were conducted via telephone whilst two interviewees provided written responses to the questions asked. Interviews typically lasted for one hour at the interviewee's place of work. A detailed description of the interviewees' profiles is presented in Table 2.

[Table 2]

The interviewees' have considerable experience in the construction sector with relevant experience on green issues. Using the five elements of the GBM as analytical themes, interviewees were asked to explain how each one of these elements had been transformed as a result of the pursuit of green practices. The interviewees were asked the following questions:

Q1: How have elements of the BM changed and will change as a result of green strategies/practices?

Q2: What conditions need to change for GBMs to be economically viable?

The interview questions were predetermined from existing empirical research (Sommer, 2012). A brief description of each element is presented to the interviewees as showed in Table 1. Data was analysed manually in a qualitative manner by considering each GBM element as a theme of transformation (Chinyio \& Akintoye, 2008). For each element, the authors have examined the transcripts to establish common transformations patterns and listened to the audio recorded materials. The researchers recorded any impressions, and initial ideas, and developed a summary contact form. The analysis was focused by question, consolidating all the data from each question. This approach allowed for better comparisons between different answers to identify consistencies and differences. The authors reported and 
presented the findings with clear connections to the existing literature where connections were possible next.

\section{Discussion of Findings}

\subsection{Green Value Proposition (GVP)}

Interviewees agreed that the customer awareness of GVP had increased, thereby encouraging supply/ provider firms in the sector to enhance their understanding of GVPs. Such an understanding would no doubt place them in a better position to offer this GVP to clients. GVP transformation can be divided into: proactive offering; active marketing by all staff; responsible offering; and offers to solving problems. For instance, respondent $\mathrm{O} 2$ hereafter stated that "we decided we need to be more proactive rather than reactive .... and to actually understand products, technology, benefits and draw back when there is presented opportunities to clients." Moreover, CS2 explained the integrative nature of the GVPs offering process wherein everyone within the firm is equipped to identify and seize opportunities before referring clients to a specialist. CS2 reiterated that "everybody needs to know about this [referring to environmental services] once you talk to a client about it and once you get to the point where client says yes it is interesting that is when you go to somebody who is an expert." Some interviewees explained that the transformation of the GVP element needed to be part of a responsible offer wherein supply/provider firms acknowledge all the advantages and disadvantages that come with the GVP whilst offering it to their clients. Therefore, the firm will assume a responsibility towards its clients by offering them best values. For example, $\mathrm{O} 2$ indicated that "we might have a client that has been told 'you need to do something green and they do not know what to do' .... we can help them develop their interpretation of green."

Another transformation related to that fact that some firms were offering the GVP to solve a client's problem. For instance, Clemphasised the need to "relate offerings more closely to resolving issues created by legislation/ regulation." $\mathrm{O} 2$ further explained the reasons behind offering GVPs to their clients, stating that "it is something that they [referring to their clients] are aware of and they need solutions to a lot of environmentally green problems and the general increasing impact of climate change begins to continue to become more apparent as energy bills continue to rise." In summary, the participants stated that GVPs are attractive for clients who manage or own large building portfolio to reduce the 
operation costs. This resonates with Bartlett \& Howard (2000) findings where they stated that cost savings in the operational phase of a building have encouraged clients to ask for green because they see a long-term economic benefit. Therefore, GVPs may entail targeting new or different type of clients or approaching clients differently as will be presented next.

\subsection{Target Group (TG)}

The TG element was shown as a major element that needs to be transformed in order to increase GBMs uptake. The emergent transformation themes can be broadly categorised in: understanding TGs need; communicating effectively; offering integrated service; being proactive; and shifting TGs focus from capital cost to whole life cycle cost.

From the data, it was evident that interviewees dealt with TG and GVP simultaneously, hence reinforcing the idea of dealing with these elements in a systemic manner (Aho, 2013; Sommer, 2012). For example, AR1 stated that "clients are generally inspirationally and naively green until they see the costs." To this end, AR1 indicated that he did work closely with clients (TG) to develop appropriate GVP to suit their budgets. Also, the interviewees maintained that they had started to offer the green solution to clients alongside standard solutions. However, they also communicated all the benefits associated with the former during this time. This approach assisted clients in making informed decisions. AR4 confirmed that " a client approached us to build her a commercial building and I said to her are you interested in building a low carbon building so I have started promoting low carbon and added value for clients. " In another example, C3 explained that his firm dealt with TG differently by offering an integrated service of design, build, and operate. This approach has helped to deliver better GVP for the TG resulting in a good relationship between the contractors and their clients. Integrated service has support from the literature where Henriskin et al., (2012) classified design, build, finance, operate (DBFO) as a GBM. The green element of this model is the coupling of the design and construction stages with the operational/maintenance stages. The responsibility of the providers to operate and maintain the asset will encourage them to design and construct buildings that can be operated and maintained in an effective way. On TGs side, DBFO provides a better solution as it delivers the projects on time and within budget. The GVP is tailored according to TGs need and provides savings and better value for money by properly maintained infrastructure. 
In the traditional $\mathrm{BM}$ of the construction sector, projects are driven and initiated by clients (TG) (Mokhlesian \& Holmen, 2012). But in GBMs, providers are taking a proactive approach and reaching out to TG. For example, C4 indicated that they knew that one of their TG had a strong focus on energy efficiency. As a result, $\mathrm{C} 4$ affirmed that "we offered them energy investment where we pay the upfront cost and they pay us back from the savings." Contributing, $\mathrm{O} 2$ observed that "we are prompting the client to think about something different." Interviewees also highlighted the importance of shifting TG focus from capital cost towards whole life cycle cost. AR4 reported that "Most of our clients do not ask this question: how much the building energy will cost me over its life cycle? And I think short term is still out there." Aho (2013) suggested that a shift is needed from cost based to performance based models (whole life cycle) to increase sustainable buildings uptake.

\subsection{Key activities $(\mathrm{KA})$}

KA are transformed as follows: promoting the benefits of being green; pursing shortterm returns; changing working practice; and extensive assessment activities. Within the sample, it was evident that firms were actively promoting and communicating the benefits and the outcomes of being green. Typical comments observed include: “....this is good for our environmental strategy and we told people what we did and what the savings are" (CL4). CL3 observed that "I suppose that it is better to communicate the outcomes of sustainability to an organisation and if you are able to do that, it will increase people's buy-in from the organisation, so it is a way of self-generating enthusiasm". CS1 indicated that "early wins" activities quicken the transformation process as firms can see some quick results emanating from waste reduction or improved energy efficiency amongst others. This approach motivates firms to adopt green practices on a larger scale owing to the tangible benefits of such to their financial bottom line.

A vital transformation depends on changing the working stream and practice. This can result from the adoption of a collaborative approach to work and the use of technology. For instance, the adoption of sensor technology can help achieve more efficient consumption of energy and water thus influencing behaviour to promote a low carbon culture and efficient practices (Bilsen et al., 2013). Also, AR1 and AR2 provided an example where they adopted offsite construction as a new method of design because they believed it will provide better environmental performance. $\mathrm{O} 2$ stressed that it is important "to look beyond of what you have done before historically, try to understand the intangible benefits."Additionally, CL1 
explained the way his firm has transformed its procurement approach. He maintained that they procured only from suppliers who meet specific criteria conforming to the green agenda. Furthermore, C4 pointed to the transformation which results from the adoption of environment-friendly practices. Central to this is his firm's adoption of zero waste and circular economy practices. The firm started to approach buildings differently and explored ways of recover and demolish buildings in a manner that is analogous to these new practices.

Firms started to transform the way people work by introducing flexible working patterns and investing in online facilities for collaboration hence reducing the travel miles. In addition, assessment activities were considered a major transformation in activities performed by green firms. Extensive assessment activities of their own environmental impact and carbon footprint were part of the day-to-day activities. These services were also extended to their clients. The environmental and carbon accounts of a given firm are vital to compete for public sector projects. CS2 pointed out that they became ISO40001 certified (the environmental management system) following their loss of a tender from the public sector, "so it is very easy decision for business to make to invest in it [referring to the ISO40001 certificate] to win the work." CS1 added that "the best firms when they do it, decide on some key performance indicators ... so you choose some performance indicators and you make that as part of how you measure things not as extra if you do not measure things they are not going to happen."

\subsection{Key resources $(K R)$}

Interviewees identified knowledge, specialist skills, and people as important KR that experienced considerable transformation. There was consensus that relevant training and indepth knowledge pertaining to green issues underwent major transformation in firms to increase the level of awareness among managers and employees. AR1, AR2, and AR4 mentioned that they had undergone different training to achieve lower environmental impact buildings. However, they agree that such trainings have to be updated, regularly, in response to market demands because green issues are still evolving and developing. In a related vein, Beltramello et al. (2013) analysed 55 case studies of new GBMs. The case studies confirmed the value of knowledge and training in fostering green growth. 
AR1 pointed out that architects need to transform their approach to designing buildings in order to achieve green buildings. In his view, they need to adopt a "fabric first" approach where they will establish "anchor information" related to performance of the building envelope. For example, a U-value for the windows and roof can be established early in the design stage and has to be fixed until the construction stage.

Furthermore, a cross-section of interviewees recognized the value of collaboration between the internal business units both vertically and horizontally. The contractors provided instances where they had received brilliant ideas from their staff. They indicated that staff was empowered to participate in the green transition. C3 stated "Most great ideas which may save money and may improve the business do not come necessarily from the sustainability team. We kind of help empower people but most of the good ideas and abilities come from staff. Basically they see a problem or challenge and they want to do something about it and they are empowered to do that." This approach can be seen as empowerment for staff who in turn promotes the green solution. This allows them to participate in finding innovative solutions.

One of the most important transformations related to the KR is the establishment of a specialist unit or environmental/ sustainability officer's position to drive the agenda. Some firms have dedicated units and others, dedicated individuals. However, this is dependent upon the firm's size. Not only can there be a specialist unit or individuals, but also some volunteering effort amongst the staff, such as an environmental champion and then it is made part of each individual's job description. This view is echoed in empirical findings obtained from firms where sustainability practices are contributing to profits and so called "Harvesters." Such findings reported lessons learnt, such as; harvesters usually change the organisational structure or adopt new structures and establish the position of sustainability officer (Kiron et al., 2012).

The interviewees stated that the decision taken by most firms for operational units or individuals responsible for environmental sustainability to report at the strategic level was indeed a transformation. In many cases, there will be a strategic board manager responsible for the operational levels. According to CS2, "how the information [referring to environmental impact information] is fed back to a higher level rather than just being left at an operational level is something which has changed in the business." $\mathrm{C} 4$ added that, "we 
have a green business report that goes up to our head office and it defines how much of our turnover we classify as green and being more environmentally acceptable."

Existing research suggested that KR and KA elements are closely linked and in most cases they transform simultaneously. The most common transformation is expected to be more complex organization of the construction business instead of current linear activities (Mokhlesian \& Holmen, 2012).

\subsection{Financial logic $(F L)$}

The interviewees denoted the transformation of the FL as follows: "economically viable in the long-term", "whole life cycle costing", and "value for money." These are consistent with our view of a systems approach to plan, test and effect a transformation.

AR1 described the change of the FL of his firm in pursuing a green/sustainability agenda as being; "economically viable in the long-term but not most profitable." This view demonstrated a deep understanding of the whole philosophy of the green movement and transition. The view has been supported by A1 who stated that economic sustainability means "the sustainable creation and investment of wealth as a result of business activities." This implies the need for firms to not only create wealth but to invest in a better future. Despite the agreement among interviewees on having a long-term view on FL, some of them asserted the importance of having realistic and short-term payback periods on green investments. They cited examples where the implementation of energy and water consumption measures had yielded good returns over a shorter period of between 2-3 years.

Interviewees frequently noted the criticality of whole life cycle costing as the FL of transiting to GMB. In most cases, firms sell GVPs to existing and potential clients with the promise of achieving a reduction in the running costs of their buildings. Also within the sample, some firms have converted their buildings into green buildings to save on maintenance and running costs. However, according to some interviewees, clients are not interested in the whole life cycle cost unless they have some sort of ownership of a building. AR1 stated that "It is going to be a period of longer tension between the cost of green solution and the ability to deliver that costly effectively."

Architects and Contractors within the sample explained that green solutions can deliver value for money through many aspects such as "value engineering," "cost effective standard 
products and systems," and "getting things 'Right First Time'." CL5 suggested that it was better for clients to "look at the whole value for that product and value for money rather than the cheapest item because it might end up cost you more."

Although the interviewees have been asked about each element individually, the close relationship between these elements was evident during the interview discussions. In most cases, the interviewees discussed the transformation of an element in relation to other elements.

\section{Research implications}

From the results, GBMs are usually initiated as a reaction to driving forces such as regulations and the desire to seize market opportunities. The internalisation of green issues can be achieved by two decisions. Firstly, an ethical decision responding to the overwhelming scientific data about climate change and environmental degradation. Secondly, a market decision to seize the green opportunities and demonstrate proficiency levels in offering green solutions. Alternately, a firm may internalise these green issues through a combination of these two decisions. Figure 1 illustrates GBMs transformation.

Figure 1

Figure 1 indicates that the transformation towards GBMs can be triggered by regulations and market demands of environmental sustainability as presented in Section 4.1. These triggers make the case for a transformation of the original BM. In this paper, a suggestion was made to adopt defined elements to aid this transformation. From the results, this case is not always systematic and firms deal with existing elements of their BM in an isolated manner. This leads to a BM transformation process which ultimately results in a new GBM. In practice, the transformation process is difficult to achieve and requires major investments in time, money, and people (Aho, 2013). The GBM elements presented in this study can help managers to structure their transformation process because these elements combine inside (value creation) and outside (value capture) views of green value analysis. From the results, it is clear that the interviewees concentrated on the inside view: KA and KR. They explained the transformation of these elements in details. However, a majority of interviewees did not provide details on GVP and TG elements (outside view). Some interviewees indicated that they dealt with the GVP and TG simultaneously; a manner which has been representing the right approach in capturing green values (Sommer, 2012). 
Based on the results presented and discussed in Section 4, the following recommendations can be offered on how firms can embark on a transformation of these elements to benefit from their environmental practices:

- Moving to GBMs will bring significant changes to the way they work. They usually start with GVPs but soon they realise that more changes have to follow to unlock GBMs potentials

- Firms wishing to transform themselves in response to environmental considerations, need to become more collaborative with stakeholders inside and outside of the firm

- Transformation starts from the strategic level (policy) to the operational level but it may be triggered by the operational level (see Section 4.4). The transformation process is continuously developing. Therefore, firms need to continuously review their approach and seek alternatives or best ways to deliver the GVP

- The GVP is related to the offer and the unique selling point of a product or service. Therefore, it becomes vital for the provider firm to understand the GVP to be offered to the TGs. This understanding plays an important role and thus each firm has to know 'why we are doing it'. The GVP should be created to meet TG needs or to solve their problems. Good firms have the ability to tailor the GVP according to TGs need and they acknowledge there is no single solution to the green problems. In other words, the GVP starts externally from TGs need but it has to be created internally by the provider. Although the GVP is always driven by TGs, firms can approach and inform potential TGs of the benefits of the GVP, hence accessing new markets

- Firms need to communicate and engage with their existing TGs to meet their expectations and search for like-minded or eco-TGs

- Firms need to change their KA to reflect the transition to GBM. The principal difference between GBM and conventional BMs is that the former performs its activities in a more environmentally friendly manner by for instance, generating less waste, using renewable sources, and consuming less energy. It was clear that the participants' firms were actively altering the KA to reflect their environmental commitments

- Wherever the need for change is recognised, eventually it will be up to the top management's commitment to create and offer the suitable KR internally and externally for the firm. People and skills are important areas for improvement but it 
will be difficult for firms to fulfil it alone. Therefore, collaboration between firms, universities, and government is highly recommended for green transition. Firms should work more closely with their supply chain to ensure that they adhere to the same principles. Larger firms may provide support for their supply chain for better results.

- Additionally, new ways of investment are needed based on value and performance but these require a strong partnership between all parties, from government and financial institutions to the construction sector in order to capture the value GBM can provide.

The results reveal the importance and the influence of each GBM element. However, the significance of the GBM concept stems from its systemic character - it is not about details of isolated elements, but how the elements are interrelated and how they strengthen each other to form a well-functioning entire system (Pekuri et al., 2014; Pekuri et al., 2013). GBMs encourage the application of systems thinking where the component parts of any system can be best understood in the context of relationships with other components and other systems, rather than in isolation (Pullen et al., 2010). Therefore, GBMs contribute to the creation of new sustainability-oriented business culture that will eventually deliver true value for the environment and the society.

A key observation among the sampled firms is that when these firms commenced the offering of GVPs to TGs, they started working on reducing their own carbon footprint. Some of them moved to paperless documentation, some adopted the application of 're-use, recover, recycle', and others changed their lighting to LED and converted their building to highly insulated buildings. This can be seen as an embedded benefit of the GBMs. This has a wider society benefit because efficient resource use will lead to sustained future for next generations.

\section{Conclusions}

GBMs transformation within UK construction sector has investigated to offer recommendations for construction firms on green transition. Five elements of GBM were adopted from extant literature: Green Value Proposition (GVP), Target Group (TG) Key Activities (KA), Key Resources (KR), and Financial Logic (FL). These elements were 
utilised as an analytical framework for this qualitative study. Semi-structured interviews were carried out with professionals from different firms of the construction value chain.

The transformation was mainly triggered by environmental regulations and increasing market demands for GVPs. Firms have increased their knowledge and provided training for their staff. It was evident that these firms have concentrated their efforts on KA and KR because these elements are directly within the firm's control where green value is created. In most cases, these elements are interlinked and transformed systematically. In addition, internal communication and collaboration have increased considerably as a result of green transformation. It is essential to engage with the supply chain to create green values.

However, GVP and TG elements received less attention despite their relevance to green value capture. This may explain why some construction firms deal with environmental requirements as a threat rather than as an opportunity. There were assumptions that creating green values will be translated into demands and profits. A better approach is to create green values to meet an existing TG requirements or to solve their problems through tailored GVPs. All interviewees highlighted the importance of FL element and agreed that GBMs require a longer term view on financial models. They also highlighted that it is difficult to find TG that are willing to take this longer view unless they maintain a form of the ownership of the GVPs. This problem needs a solution involving wider stakeholders engagement including financial institutions and government support. It is recommended that construction managers should pay more attention to the outside view of the GBM: GVP and TG because capturing value from green activities rely on these elements. It is therefore essential to establish or enhance staff capacity around green marketing skills to engage with existing clients and identify new clients with green demands. It is also recommended to address the five elements systemically thus the different elements of the GBM should never be transformed in isolation. Research findings have led to a confirmation of a conceptual framework for GBMs transformation process. The findings can help managers develop new ways of green value creation and capture; thus contributing to the implementation of green practices. They also reinforce the importance of a systemic approach along supply chains to identify and capture the impact of green practices in building development

For the further advancement of the outlined GBM transformation, it has to be subjected to the scrutiny of more interviews to cover a wider range of construction value chain actors. 


\section{References}

Aho, I. (2013), "Value-added business models: Linking professionalism and delivery of sustainability", Building Research \& Information, 41(1), 110-114.

Amaratunga, D., Baldry, D., Sarshar, M., \& Newton, R. (2002), "Quantitative and qualitative research in the built environment: application of "mixed" research approach", Work Study, 51(1), 17-31.

Bartlett, E., \& Howard, N. (2000). Informing the decision makers on the cost and value of green building. Building Research \& Information, 28(5-6), 315-324.

Beltramello, A., Haie-Fayle, L., Pilat, D. ( 2013) Why New Business Models Matter for Green Growth. OECD Publishing, Paris.

Bilsen, V., Blondiau, T., Debergh, P., \& Lukach, R. (2013), Exchange of good policy practices promoting Innovative/Green Business Models, European Commission, Directorate-General Enterprise \& Industry.

Bocken, N.M.P., Short, S.W., Rana, P., \& Evans, S. (2014), "A literature and practice review to develop sustainable business model archetypes", Journal of Cleaner Production, $65,42-56$.

Bryman, A. (2012), Social research methods. Oxford: Oxford University Press.

Chinyio, E. A., \& Akintoye, A. (2008). Practical approaches for engaging stakeholders: findings from the UK. Construction Management and Economics, 26(6), 591-599.

Creswell, J. W. (2007), Qualitative Inquiry and Research Design: Choosing among five approaches (2nd ed.). Thousand Oaks, California: Sage Publications.

Denzin, N. K., \& Lincoln, Y. S. (2008), Collecting and interpreting qualitative materials (Vol. 3): Sage Publications, Incorporated.

Henriksen, K., Bjerre, M., Almasi, A. M., \& Damgaard-Grann, E. (2012), Green Business Model Innovation: Conceptualization report. Nordic Innovation Publication Oslo, Norway.

Hyde, K. F. (2000), "Recognising deductive processes in qualitative research", Qualitative Market Research: An International Journal, 3(2), 82-90.

Jing, H., \& Jiang, B. S. (2013), “The framework of green business model for eco-innovation”, Journal of Supply Chain and Operations Management, 11(1), 33-46.

Kiron, D., Kruschwitz, N., Haanæs, K., Velken, I. V. O. N. S., Reeves, M., \& Audretsch, M. (2012), Sustainability nears a tipping point. MIT Sloan Management Review, 53(2), 69-74.

Lambert, S. C., \& Davidson, R. A. (2013), "Applications of the business model in studies of enterprise success, innovation and classification: An analysis of empirical research from 1996 to 2010", European Management Journal, 31(6), 668-681.

Mokhlesian, S., \& Holmén, M. (2012), "Business model changes and green construction processes", Construction Management and Economics, 30(9), 761-775. 
Osterwalder, A. (2004), "The business model ontology: A proposition in a design science approach", Academic Dissertation, Universite de Lausanne, Ecole des Hautes Etudes Commerciales, 2.

Osterwalder, A., \& Pigneur, Y. (2010), "Business model generation: a handbook for visionaries, game changers, and challengers": Wiley.

Pan, W., \& Goodier, C. (2011), "House-building business models and off-site construction take-up", Journal of Architectural Engineering, 18(2), 84-93.

Pekuri, A., Pekuri, L., \& Haapasalo, H. (2013), "The role of business models in Finnish construction firms", Australasian Journal of Construction Economics and Building, The, 13(3), 13.

Pekuri, A., Suvanto, M., Haapasalo, H. and Pekuri, L. (2014), "Managing value creation: the business model approach in construction", Int. J. Business Innovation and Research, Vol. 8, No. 1, pp.36-51.

Pullen, S., Arman, M., Zillante, G., Zuo, J., Chileshe, N., \& Wilson, L. (2010), "Developing an assessment framework for affordable and sustainable housing", Australasian Journal of Construction Economics and Building, 10(1/2), 48-64.

Raynsford, N. (1999), "The UK's approach to sustainable development in construction", Building Research \& Information, 27(6), 419-423.

Renukappa, S., Egbu, C., Akintoye, A., \& Goulding, J. (2012), "A critical reflection on sustainability within the UK industrial sectors", Construction Innovation: Information, Process, Management, 12(3), 317-334.

Rhodes, C. (2014), The construction industry: statistics and policy. House of Commons, London.

Selberherr, J. (2015), "Sustainable life cycle offers through cooperation", Smart and Sustainable Built Environment, Vol. 4 Iss 1 pp. $4-24$.

Sommer, A. (2012), Managing green business model transformations. Verlag Berlin Heidelberg: Springer.

Teece, D. J. (2010), "Business Models, Business Strategy and Innovation", Long Range Planning, 43(2-3), 172-194.

Walravens, N. (2015) Qualitative indicators for smart city business models:The case of mobile services and applications. Telecommunications Policy 39 218-240.

Zhao, X. \& Pan, W. (2015) Delivering zero carbon buildings: The role of innovative business models. International Conference on Sustainable Design, Engineering and construction, Procedia Engineering, 118 404-411 